\title{
¿ES LA CATARATA LA OPACIFICACIÓN DEL CRISTALINO? (I) Estudio sobre textos medievales 1. Etimología y doctrina médica
}

\author{
DIAB HAGGI $F^{1}$
}

La palabra catarata tiene su origen en la lengua griega antigua y expresa el hecho de caer con fuerza o despeñarse (1). Procede de la palabra griega Katarráktēs compuesta por katá prefijo que indica «hacia abajo», rrák derivado del verbo que alude a «tirarse encima de» y finalmente por tês sufijo que hace referencia a instrumento. Por tanto, Katarráktess es aquello que se precipita desde arriba; y tiene en griego dos significados básicos, «cascada»o «rastrillo de puerta fortificada» (2) y ambas acepciones expresan caída enérgica, valga la redundancia, desde arriba. Hasta aquí, no hay en dicho término ninguna alusión explícita y directa a patología médica ni oftalmológica.

Sin embargo, los textos médicos griegos para referirse a la enfermedad que enturbia, reduce y puede llegar a impedir la visión, superponible al cuadro clínico que reconocemos en la actualidad como catarata, acuñaron el término específico Hypókhyma que significa en griego «flujo que desciende».

Así pues, tanto el término Katarráktēs como hypókhyma sugieren algo que DESCIENDE sea agua, flujo, rastrillo, verja o celosía y, además, en este descenso lleva implícito la acción de impedimento.

En la evolución histórica dichos términos no han tenido la misma suerte. Katarráktees pasó al latín, con los mismos significados, como cataractees y más tarde cataracta; el término hypókhyma pasó, por calco, es decir mantener el significado de una lengua bajo la cubierta externa de otra, a suffüsiōn como su equivalente latino. El término katarráktess desplazó al término médico propio hypókhyma y del mismo modo cataracta desplazó a suffūsiōn.

Fue en el s. XI, nada menos que Constantino el Africano (Cartago, Túnez c. 1015 d.C.-Montecassi- no, Italia 1087) de la Escuela de Traductores de Salerno y autor de las primeras versiones latinas de obras médicas en lengua árabe, el primero en usar el término cataracta para aludir a la enfermedad que nos ocupa. Tened en cuenta que la Escuela de Traductores de Toledo s. XII junto a la de Salerno s. XI fueron las que llevaron a cabo, fundamentalmente, la labor de traducción, preferentemente al latín, de los textos médicos y de otras ciencias, en lengua árabe, del medievo, sin olvidar las traducciones aportadas por la corte siciliana de Federico II, s. XIII, y la de Sta. María de Ripoll, mediados del s. X, entre otras localidades en la península ibérica. Estas traducciones fueron la base, más bien la cuna, del Renacimiento junto con la labor de los médicos humanistas.

El castellano, s. XIII, fue la primera lengua moderna donde está documentado, en 1250, la aparición del término cataracta.

Actualmente, la palabra catarata, según el contexto de la frase puede evocar la imagen bella y refrescante de un salto grande de agua o nos sitúa ante esta patología ocular que Cajal describió como «el telón que ocultaba el mágico teatro de la vida».

Si contemplamos una catarata en el curso de un río podemos observar que se ha producido por el descenso del agua y que el fluido transparente en su caída se vuelve opaco, blanco y lechoso. Quizás para frasear la naturaleza y designar un nombre a la enfermedad ocular que como telón va reduciendo la visión, se ha escogido el término descenso del agua traducción literal del término árabe nuzūl alma título con que Ibn Sīnā (Afs̃ana, Bujara, Uzbekistán 980 d.C-Hamadan, Irán 1037) encabeza en su Canon, el capítulo sobre las cataratas (3). Girolamo Fabrizi d'Acquapendente (Acquapendente 1537-Padua 1619) catedrático de cirugía de la Uni-

\footnotetext{
1 Doctor en Medicina y Cirugía.

E-mail: fathidiab@terra.es

Comunicación presentada en la VI Reunión del Grupo de Historia y Humanidades en Oftalmología (76 Congreso de la S.E.O. Madrid 2000). Actualizada.
} 
versidad de Padua en su «Crisol de la Cirugía» bajo el título «De la sufusión, o cataracta» dice textualmente «Los latinos la llaman "sufusión", y los griegos "hypochyma", los árabes "agua", según Albucasis, "lib. 2. cap. 23" y Avicena "lib. 3. fen. 3. tract. 4. cap. 18". Y vulgarmente se llama "cataracta", tomando la denominación a mi entender de aquellas puertas que en las plazas, y castillos caen de arriba hacia abajo, e impiden de todo punto el paso, que llaman rastillos: porque la catarata cayendo de alto, esto es, de la cabeza a los ojos quita el paso a la luz y a la vista» (4). La elección del término «descenso del agua» es compatible dentro del marco histórico doctrinal de la medicina medieval. Para comprenderlo hay que conocer las teorías doctrinales dominantes, la concepción estructural de los componentes oculares y la naturaleza y ubicación de la opacidad que va limitando la visión.

Las doctrinas del arte de sanar $(5,6)$ de la medicina de los pueblos primitivos y de las culturas arcaicas, tanto las extinguidas como la medicina asirio-babilónica, la del antiguo Egipto y la del antiguo Irán, como las pervivientes representadas por la China antigua, la de la India antigua, la precolombina, la del Extremo y Medio Oriente, incluso la pretécnica griega, todas ellas tienen una concepción mágico-teúrgico de la enfermedad. Hacia el año 500 a. C surge, en Grecia un momento estelar en la historia de la medicina y ésta da un enorme salto cualitativo gracias a la introducción de dos conceptos básicos:

1. La Physis o naturaleza, concepto elaborado en la costa de Asia Menor o Jonia, como el primer principio racional de todas las cosas del universo. Cualquier naturaleza particular, astro, árbol, ser humano o sus componentes, está formada por elementos irreductibles cuya diversa combinación determina la diversidad de las múltiples cosas que percibimos. Así pues, el concepto de naturaleza es tan decisivo en la historia de la medicina que se consolida como un elemento crucial y transformador.

2. Tekhne, arte o técnica que se aplica cuando quien la practica sabe qué hace y por qué hace lo que hace. Lo cual, como Aristóteles enseñó, supone conocer científicamente qué es la enfermedad en cada caso y qué es el remedio que en cada caso se emplea.

Estos dos conceptos de Physis y Tekhne transformaron la medicina empírico-mágica en medicina científico-técnica. La innovación en el quehacer médico fue plasmada, por varios autores griegos, en un número importante de obras médicas que fueron reunidas en la biblioteca de Alejandría, s. III a.C, rotulándose la colección así formada «Corpus Hippocraticum» en honor al más ilustre médico griego, Hipócrates (Isla de Cos, Mar Egeo c.460 a.C.-Larissa, Tesalia, Grecia 377 a.C). En los libros del «Corpus Hippocraticum» se encuentra explicada la doctrina del enfermar elaborada por los médicos griegos a partir de tres fuentes principales:

1. Teoría de Alcmeón de Crotona (Crotona, sur Península Itálica c.500 a.C) iniciador, en Occidente, de la medicina antigua como ciencia médica. Alcmeón, que era dualista, concebía como punto de partida los estados de armonía y desarmonía como sustrato de salud y enfermedad. La armonía sería el resultado del equilibrio o justa proporcionalidad, distinta en cada individuo, que guardaría entre sí el par de cualidades opuestas de Alcmeón: lo húmedo y lo seco, lo frío y lo cálido, lo amargo y lo dulce, lo blanco y lo negro y los demás... El predominio de alguna cualidad sobre las otras ocasionaría la desarmonía y causaría la enfermedad.

2. Teoría de Empédocles (Agrigento, costa oeste de Sicilia c. 490 a.C-¿?, 430 a. C). Identifica los elementos irreductibles de cada naturaleza como los primeros elementos eternos, indestructibles y constituyentes del cosmos: el agua, el aire, la tierra y el fuego; cada uno de estos cuatro elementos es, a su vez, una mezcla peculiar de los cuatro, en la cual el elemento en cuestión predomina.

Casi un siglo más tarde Aristóteles (Estagirita, Macedonia c. 385 a.C-Calcis, Eubea, Grecia c. 322 a.C) asigna a cada uno de los cuatro elementos de Empédocles un par de cualidades opuestas de Alcmeón; así pues el aire será caliente y húmedo; el agua, fría y húmeda; la tierra, fría y seca y el fuego, caliente y seco.

3. Experiencia personal. Basada en un juicio racional sobre la particular naturaleza del enfermo, del enfermar y de los remedios terapéuticos y ejercida a lo largo del tiempo, apoyándose en el legado de conocimientos aportados por insignes figuras del pensamiento de su época.

La teoría de Empédocles, con la aportación aristotélica, predomina y perdura, más que la doctrina atomista de Demócrito, entre los médicos del «Corpus Hippocraticum»; en estos textos surge una nueva noción basada en el «humor» (Khymós) (7) siendo éste un fluido más o menos viscoso que permanece inmutable en todas las transformaciones normales de la naturaleza del cuerpo humano. La géne- 
sis del humor es el resultado de la mezcla, en cuatro proporciones diversas, de los cuatro elementos de Empédocles. El número de los humores que se consolida como referencia es el que Pólipo, yerno de Hipócrates, expone en su libro «Sobre la naturaleza del hombre» siendo estos cuatro: La sangre, la bilis amarilla o cólera, la bilis negra o melancolía y la pituita o flema. Dado que los elementos, ya con sus dobles cualidades asignadas por Aristóteles, van a originar los humores, éstos a su vez serán también soporte y agente de un par de cualidades opuestas así pues la sangre será caliente y húmeda; la bilis amarilla, caliente y seca; la bilis negra, fría y seca y la pituita, fría y húmeda. A partir de este concepto los médicos del «Corpus Hippocraticum» elaboran la Doctrina Humoral.

Esta doctrina concibe como principio esencial de la vida, propio y connatural del organismo, al «calor innato». Esta concepción es el reflejo de la superioridad cosmobiológica de «lo cálido» sustentado por el fuego; y así aparece en los planteamientos de Heráclito (Éfeso, Asia Menor, c. 540 a.C.-480 a.C.) y Pitágoras (Isla de Samos, 582 a.C.-Crotona, ?). Este último influyó en Alcmeón, Parménides, Platón, Euclides, Empédocles, y Keppler. En cambio, Diógenes de Apolonia (Creta, c. 460 a.C.) concede primacía al aire y será el iniciador, junto a otros, de la doctrina del neumatismo.

Según la doctrina humoral el calor innato se aloja en el corazón y es sostenido por el neuma, o aire inspirado; la transformación de los alimentos por la acción del calor innato generaría los humores cardinales; la proporcionalidad de estos humores, según cada individuo, mantendría el estado de salud (eucrasia); su perturbación, ya no por génesis mágica o teúrgica, será siempre originada por causas naturales, ambientales o dependientes del propio individuo, ocasionaría los estados de enfermedad (discrasia). Eucrasia y discrasia son equivalentes a los estados de armonía y desarmonía concebidos por Alcmeón. Las porciones digeribles de los alimentos pasan a la sangre venosa y ésta, una vez depurada de sus residuos, orina en el riñón, exceso de bilis negra en el bazo, y aireada en el pulmón se transforma en sangre arterial que se conduce hacia el cerebro, allí éste se nutre y en él se forman los sutiles pneumas psíquicos o espíritus animales, que pasan a la médula espinal y a los nervios como agentes inductores de la sensación y del movimiento. Entre estos pneumas está el espíritu visual que es canalizado por los nervios ópticos ahuecados (8). La nutrición de las partes periféricas origina residuos que serían el sudor, las lágrimas, el sebo cutáneo, el pelo y las uñas.

La doctrina humoral es la de mayor pervivencia en la historia de la medicina, logró una vigencia casi de más de diecinueve siglos pues dominó todo el pensamiento médico desde s. III a.C., la Antigüedad, toda la Edad Media, el período del Renacimiento y permaneció hasta los comienzos de la etapa propiamente moderna s. XVII.

\section{BIBLIOGRAFÍA}

1. Diccionario de la Lengua Española. XX Ed. Madrid: Real Academia Española; 1984; I.

2. Cortés Gabauden F. Diccionario médico- biológico, histórico y etimológico. Salamanca: Universidad de Salamanca; 2004. www.dicciomed.es

3. Ibn Sīnā. Alqā̄un fī Alț̣ib. Cairo: Būlāq; 1877; libro III, fen III, tratado IV, cap VIII:145. Unánimemente reputada como la mejor edición existente en lengua original.

4. Aquapendente JF. Crisol de la cirugía. Traducción González de Godoy P. Valencia; 1676. Opúsculo Laboratorios del Norte V; Masnou, Barcelona; 1928; II; cap XVI: 7.

5. Laín Entralgo P. Historia de la Medicina. Barcelona: Salvat; 1982; 43-90.

6. Granjel Luis S. Historia de la Medicina. III Ed. Salamanca; $1975 ;$ 55-65.

7. Tratados Hipocráticos. Madrid: Gredos; 1997; II: 89-117.

8. Diab Haggi F. La Oquedad del nervio óptico. Arch Soc Esp Oftalmol 2001; 76: 133-134. 